\title{
Impact of telmisartan in modifying vascular risk
}

\author{
This article was published in the following Dove Press journal: \\ Integrated Blood Pressure Control \\ 10 June 2010 \\ Number of times this article has been viewed
}

\section{Jean-Philippe Baguet \\ Olivier Ormezzano \\ Gilles Barone-Rochette \\ Clinique de Cardiologie, Centre Hospitalier Universitaire de Grenoble, Grenoble, France}

Correspondence: Jean-Philippe Baguet Clinique de Cardiologie, Centre Hospitalier Universitaire de Grenoble, BP 217, 38043, Grenoble Cedex 09, France

Tel +33476768480

Fax +33476765559

Email jpbaguet@chu-grenoble.fr
Abstract: Telmisartan, a selective angiotensin II type 1 receptor blocker (ARB), has been investigated in many trials, in particular, in order to assess its antihypertensive effect in various situations and its ability to protect organs susceptible to hypertension. In addition to its antihypertensive properties, it has positive metabolic and vascular effects (partly because of its sustained action). Several large-scale trials have focused on the effect of telmisartan on cardiovascular morbidity and mortality, including comparisons of that with an angiotensinconverting enzyme inhibitor in subjects at high vascular risk. Telmisartan was used in the largest ARB research programme (the Ongoing Telmisartan Alone and in Combination with Ramipril Global Endpoint Trial [ONTARGET] and Telmisartan Randomized Assessment Study in ACE Intolerant Subjects with Cardiovascular Disease [TRANSCEND] trial).

Keywords: angiotensin II receptor blocker cardiovascular risk, hypertension, blood pressure, renin-angiotensin-aldosterone system

\section{Blood pressure and vascular risk management}

Hypertension is an extremely common pathology worldwide, and its effects on certain organs, such as the heart, the arteries, the kidneys, and the brain or retina, are well characterized. Many trials have shown that hypertension is a continuous, independent risk factor for cardiovascular (CV) disease. Once a patient has been diagnosed with hypertension, the practitioner should assess the cause and effects of the hypertension before initiating the pharmaceutical treatment. ${ }^{1}$ It is also important to assess the overall $\mathrm{CV}$ risk of the patient with hypertension, which is evaluated on the basis of not only blood pressure (BP) readings but also other risk factors such as age, gender, dyslipidemia, diabetes mellitus, smoking, and excess abdominal weight or obesity. Risk should also be estimated using specific markers, such as albuminuria or increased plasma creatinine, left ventricular hypertrophy (LVH), and subclinical vascular damage, and preexisting $\mathrm{CV}$, cerebrovascular, and renal pathologies are also taken into account. ${ }^{2}$ Once overall CV risk has been assessed, it should be taken into account for planning the treatment strategy, and all of the following variables can be adjusted: initiation time; therapeutic class and even the specific molecule used; dosage; monotherapy or combination therapy from the outset; and prescription of a lipid-lowering drug, an antidiabetic drug, or an antiplatelet drug. In all cases, it is essential to advise the patient about diet and lifestyle factors. 


\section{Patient adherence: monotherapy vs combination therapy}

Whether first-line treatment for hypertension should be based on a single drug or a combination will not be addressed here. However, once antihypertensive treatment is indicated, everything must be done to ensure that it is as effective as possible, meaning that individual BP targets must be met and the regimen must be tolerated. The patient's compliance is dependent on both these parameters. If the BP targets are reached, especially if they are reached quickly, and if the treatment is well tolerated, compliance is more likely. Another significant factor is the number of tablets to be taken by the patient each day. In 18,806 newly diagnosed patients with hypertension older than 35 years, significant positive correlation was shown between combination antihypertensive therapy and compliance. ${ }^{3}$ In the same trial, good compliance was associated with a $38 \%$ decrease in the risk of CV events when compared with poor compliance. These findings indicate that well-tolerated treatments that are effective at lowering the $\mathrm{BP}$ and preventing $\mathrm{CV}$ events are the way forward, as are fixed combinations in cases of multiple antihypertensive therapy. However, the optimal drug treatment management and education with the aim of reducing $\mathrm{CV}$ risk comes at a price. A recent trial showed that the most effective approaches to improving compliance with antihypertensive (and also lipid-lowering) therapy are intensive and multifaceted and are therefore likely to be expensive. ${ }^{4}$

\section{Pharmacology and the effect of telmisartan on biological parameters and the endothelium Pharmacology}

The renin-angiotensin-aldosterone system (RAAS) is involved in most of $\mathrm{CV}$, cerebral, and renal problems. Its activation is an adaptive mechanism, but it can become overactive, leading to hypertension, heart failure, and impaired glomerular function. Angiotensin II-mediated activation of the angiotensin II type 1 (AT1) receptor has numerous effects, such as vasoconstriction, sodium and water retention, vascular and myocardial fibrosis and hypertrophy, and sympathetic nervous system activation ${ }^{5}$ (Table 1). RAAS blockade is used for therapeutic reasons in various branches of medicine, hence the development of aldosterone antagonists, angiotensin-converting enzyme (ACE) inhibitors, AT1 receptor blockers (ARBs), and more recently a direct renin inhibitor (aliskiren).

On physiological and pathophysiological levels, ARBs antagonize angiotensin II more effectively than ACE inhibitors, in particular, by suppressing the effect of
Table I Biological effects of telmisartan

Angiotensin II type I receptors blockage
$\downarrow$ activation of sympathetic nervous system
$\downarrow$ endothelin secretion
$\uparrow$ NO activity
$\downarrow$ vasoconstriction
$\downarrow$ vascular and myocardial growth/hypertrophy and fibrosis
$\downarrow$ apoptosis
Improvement in endothelial function
$\downarrow$ sodium and water retention
$\downarrow$ platelet aggregation
Anti-thrombotic effect
$\downarrow$ systemic inflammation
$\downarrow$ oxidative stress

Angiotensin II type 2 receptors stimulation

$\downarrow$ vascular and myocardial growth/hypertrophy and fibrosis Cell differentiation

Vasodilatation

Other mechanisms

Stimulation of PPAR- $\gamma$

$\uparrow$ insulin sensitivity

$\downarrow$ glucose and triglycerides levels

$\uparrow$ adiponectin levels

Abbreviations: NO, nitric oxyde; PPAR- $\gamma$, peroxisome proliferator-activator receptor- $\gamma$.

angiotensin II produced by alternative enzyme pathways such as those based on trypsin, cathepsin, and heart chymase. Furthermore, contrary to ACE inhibitors, ARBs do not suppress, and in fact even increase, angiotensin II subtype 2 (AT2) receptor stimulation, thereby inhibiting vascular growth and apoptosis and promoting cell differentiation and vasodilatation.

Seven active oral ARBs - losartan, irbesartan, valsartan, candesartan, telmisartan, eprosartan, and olmesartan - are currently used in clinical practice. Among these ARBs, telmisartan has an advantageous kinetic profile with a longer half-life, higher lipophilicity, larger distribution volume, and negligible renal clearance. ${ }^{6,7}$ These properties mean that it can readily enter the tissue compartments by effectively blocking the RAAS (insurmountable angiotensin II inhibition) both systemically and locally. Moreover, telmisartan blocks the AT1 receptor for longer and has a greater binding affinity than other ARBs. ${ }^{6-8}$ Its affinity for the AT1 receptor is 3,000 times higher than its affinity for the AT2 receptor. ${ }^{9}$ It also dissociates from AT1 receptors very slowly, which explains its sustained action. ${ }^{8,10}$ Results of pharmacological trials have led to a recommended dose of 20-80 $\mathrm{mg}$ for hypertension.

\section{Biological effects}

Many trials have shown that agents that target the RAAS have positive effects on thrombosis, platelet aggregation, and 
inflammation, although these effects vary from one compound to another. In a 1-month trial conducted on 36 patients with hypertension (16 treated with telmisartan and 20 with the ACE inhibitor perindopril), telmisartan had a better anticoagulant and rheological effects than perindopril, with decreases in the levels of soluble endothelial protein $\mathrm{C}$ receptor and fibrinogen. ${ }^{11}$

Telmisartan has a particularly attractive metabolic profile when compared with other ARBs. It is the strongest stimulator of peroxisome proliferator-activated receptor- $\gamma$ (PPAR- $\gamma$ ), an intracellular regulator of lipid and glucose metabolism, exerting anti-inflammatory, antioxidative, and antiproliferative effects on vascular cells. ${ }^{12,13}$ This property explains its beneficial metabolic effects - which are unique among the ARBs - on glucose and triglyceride levels and insulin sensitivity. ${ }^{14}$ In patients with hypertension with impaired glucose tolerance, telmisartan improves insulin resistance more effectively than losartan. ${ }^{15}$ It has been clearly demonstrated that ACE inhibitors and ARBs lead to the development of fewer new cases of type 2 diabetes. ${ }^{16}$ In the Ongoing Telmisartan Alone and in Combination with Ramipril Global Endpoint Trial (ONTARGET), telmisartan $80 \mathrm{mg}$ was as effective as ramipril $10 \mathrm{mg}$ in preventing new-onset diabetes in patients at high vascular risk. ${ }^{17}$ This is significant when we consider that, in the Heart Outcomes Prevention Evaluation (HOPE) trial, there was a relative risk reduction of $34 \%$ for diabetes in the ramipril group when compared with placebo group. ${ }^{18}$

Recently, a substudy of the Telmisartan versus Ramipril in Renal Endothelium Dysfunction (TRENDY) trial, including 87 patients with type 2 diabetes, showed that telmisartan leads to a significant increase in adiponectin (a peptide hormone produced in adipose tissue) compared with ramipril. ${ }^{19}$ This is particularly interesting because adiponectin has beneficial effects on atherogenesis, endothelial function, vascular remodeling, inflammation, and insulin resistance. ${ }^{20}$

\section{Telmisartan and endothelial dysfunction}

Endothelial dysfunction is now a recognized marker for $\mathrm{CV}$ risk. ${ }^{1}$ Many conditions, including hypertension and diabetes, are associated with endothelial dysfunction. RAAS blockers appear to be a particularly interesting solution to this vascular anomaly. A recent trial on patients with hypertension with impaired glucose tolerance showed that telmisartan improved endothelial function (brachial flow-mediated dilatation) to a greater extent than did losartan. ${ }^{15}$ In patients with type 2 diabetes, both telmisartan 40-80 mg and ramipril 5-10 mg significantly increased nitric oxide (NO) activity in the renal endothelium. ${ }^{21}$ This positive effect on endothelial function goes a long way in explaining why telmisartan improves vascular prognosis.

\section{Antihypertensive efficacy and end-organ protection Telmisartan: proven efficacy against hypertension}

Several trials and a meta-analysis have assessed BP-lowering effect of telmisartan. ${ }^{22}$ In the meta-analysis, the mean clinical BP reduction observed in 408 patients with grade 1-2 hypertension after 8-12 weeks administration of telmisartan $40-80 \mathrm{mg}$ was $-15.5 \mathrm{mmHg}$ for systolic BP and $-11.3 \mathrm{mmHg}$ for diastolic BP. Naturally, telmisartan was not only compared to placebo but, more interestingly, also compared to other antihypertensive agents, including ACE inhibitors and ARBs. The Preferred Reporting Items for Systematic Reviews and Meta-Analyses (PRISMA) 1 and 2 trials compared the efficacy of telmisartan $40-80 \mathrm{mg}$ with that of ramipril 5-10 mg on 24-hour BP readings. ${ }^{23-25}$ BP decreased more sharply with telmisartan $80 \mathrm{mg}$ than with ramipril $10 \mathrm{mg}(-12.7 /-8.8 \mathrm{mmHg}$ vs $-7.9 /-5.4 \mathrm{mmHg}$, $P<0.0001)$, especially in subjects with a marked morning BP surge.

Telmisartan $80 \mathrm{mg}+$ hydrochlorothiazide(HCTZ) was compared with valsartan $160 \mathrm{mg}+\mathrm{HCTZ}$ in an 8-week trial of 1,181 patients with hypertension. ${ }^{26} \mathrm{BP}$ decreased more sharply in the telmisartan group than in the valsartan group (-24.6/-18.2 $\mathrm{mmHg}$ vs $-22.5 /-17.0 \mathrm{mmHg}, P<0.05)$. The antihypertensive effect of telmisartan was greater than not only that of valsartan but also that of losartan. ${ }^{27,28}$ Thus, in a trial comparing the antihypertensive efficacy of telmisartan 40 or $80 \mathrm{mg}+$ HCTZ and losartan $50 \mathrm{mg}+\mathrm{HCTZ}$ in 805 patients with grade 1-2 hypertension, both telmisartan doses were more effective than losartan at normalizing BP in the 6 hours preceding the morning dose. ${ }^{29}$

Telmisartan has also been shown to be effective against hypertension in overweight and obese patients with diabetes. In the SMOOTH trial conducted on 840 patients who presented these comorbidities, telmisartan $80 \mathrm{mg}+\mathrm{HCTZ}$ was more effective than valsartan $160 \mathrm{mg}+\mathrm{HCTZ}$ at lowering the 24-hour BP over 10 weeks, and over the last 6 hours of the therapeutic window. ${ }^{30}$ Elderly patients with difficult-tocontrol isolated systolic hypertension have also benefited from telmisartan. Thus, the ATHOS trial of 872 subjects older than 60 years showed that BP decreased more sharply over 24 hours with telmisartan 40-80 mg (+HCTZ $12.5 \mathrm{mg}$ ) treatment than with amlodipine $5-10 \mathrm{mg}$ (+HCTZ $12.5 \mathrm{mg}$ ) treatment. ${ }^{31}$ In this trial, the percentage of patients with 
controlled systolic BP was higher in the telmisartan group than in the amlodipine group $(65.9 \%$ vs $58.3 \%, P=0.02)$.

Finally, a recent analysis of 24-hour ambulatory BP data from the ONTARGET showed that telmisartan was more effective in controlling nocturnal BP than ramipril. ${ }^{32}$

These positive results with telmisartan are due not only to its BP-lowering efficacy but also to its long duration of action.

\section{Telmisartan's efficacy against end-organ damage}

\section{Renal disease}

CV risk factors underlie arterial, myocardial, cerebral/ocular, and renal lesions. Among these risk factors, hypertension and diabetes are key factors, particularly in the development of nephropathy. It is therefore essential not only to prevent existing renal lesions from worsening (secondary prevention), but also to prevent the formation of lesions in the first place (primary prevention). Recommendations on treating patients with hypertension and/or diabetes emphasize the potential benefit of RAAS inhibitors, in particular, when the patients have renal failure and/or proteinuria. ${ }^{1,33}$ Among the RAAS inhibitors, several trials have shown that ARBs merit a special place, particularly in patients with type 2 diabetes. ${ }^{34-36}$ Telmisartan is one of the drugs that have proven their worth in this area.

The INNOVATION trial, conducted on 514 hypertensive or normotensive subjects with type 2 diabetes and microalbuminuria but no renal failure, showed that both doses of telmisartan $80 \mathrm{mg}$ and $40 \mathrm{mg}$ slowed down the appearance of overt nephropathy when compared with placebo $(16.7 \%$, $22.6 \%$, and $49.9 \%$, respectively, after a mean follow-up period of 1.3 years). ${ }^{37}$ This positive effect of telmisartan has been observed in patients with hypertension, regardless of their BP.

The DETAIL trial of 250 patients with type 2 diabetes and incipient nephropathy showed that telmisartan 40-80 mg and enalapril $20 \mathrm{mg}$ had similar effects on the progressive loss of glomerular filtration function over a 5 -year period. ${ }^{38}$

The AMADEO trial of 860 patients with type 2 diabetes with overt nephropathy (morning spot urine protein-tocreatinine ratio of 700 or more) demonstrated that telmisartan $40 \mathrm{mg}$ preserved kidney function more effectively than losartan $50 \mathrm{mg} .{ }^{39}$ In this trial, proteinuria reduced after 52 months by $29 \%$ with telmisartan compared with only $20 \%$ with losartan $(P<0.05)$ treatment, independently of the decrease in BP.

The VIVALDI trial found similar reductions in proteinuria with telmisartan $80 \mathrm{mg}$ and valsartan $160 \mathrm{mg}$ in
885 patients with hypertension and type 2 diabetes (proteinuria $\geq 900 \mathrm{mg} / 24$ hour and serum creatinine $\leq 3.0 \mathrm{mg} / \mathrm{dL}$ ) over the 52 weeks of the trial. ${ }^{40}$

The ARAMIS trial of 614 patients, who did not necessarily have diabetes, with isolated systolic hypertension and albuminuria $>2.2 \mathrm{mg} / \mathrm{L}$ showed that the reduction in urinary albumin excretion was greater in the telmisartan 20-80 mg group than in the HCTZ $12.5 \mathrm{mg}$ group. ${ }^{41}$

A recent meta-analysis indicated that the combination of an ACE inhibitor and an ARB reduces proteinuria to a greater extent than does either drug alone. ${ }^{42}$ With respect to the efficacy of this combination vis-à-vis renal function and CV events, one of the aims of the ONTARGET (this trial will be explained later in greater detail) was to investigate the long-term nephrological outcome in 25,620 subjects at high vascular risk, taking telmisartan $80 \mathrm{mg}$ vs ramipril $10 \mathrm{mg}$ or a combination of these 2 drugs. ${ }^{17}$ After a follow-up period of 56 months, the primary renal end point (a composite parameter of dialysis, doubling of serum creatinine, and death) was similar for both telmisartan (13.4\%) and ramipril $(13.5 \%)$, but was superior with the combination therapy $(14.5 \%, P=0.037) .{ }^{43}$ The estimated glomerular filtration rate decreased less with ramipril than with telmisartan $(-2.82 \mathrm{vs}$ $-4.12 \mathrm{~mL} / \mathrm{min} / 1.73 \mathrm{~m}^{2}, P<0.0001$ ) or combination therapy $(-6.11, P<0.0001)$, but urinary albumin excretion increased less with telmisartan $(25 \%, P=0.033)$ and combination therapy $(22 \%, P=0.0028)$ than it did with ramipril $(32 \%)$. In light of these results, we can conclude first that renal protection is identical with ARBs and ACE inhibitors in the high vascular risk population, and second that a serious renal event, as well as hypotensive symptoms and syncope, is more likely to occur with the combination of ARB and ACE inhibitor. This combination should therefore be prescribed only to patients with heart failure that is not controlled by ACE inhibitors ${ }^{44,45}$ (it is the only licensed indication).

\section{Left ventricular hypertrophy}

Although LVH does not have a direct effect on vascular risk, it is important to be aware of the impact of any given antihypertensive agents on this pathological process. Some trials have shown that telmisartan significantly reduces LVH in patients with hypertension. In fact, telmisartan induces greater $\mathrm{LVH}$ regression than carvedilol, ramipril, and HCTZ, despite comparable BP reductions. ${ }^{46-48}$ In the ONTARGET and Telmisartan Randomized Assessment Study in ACE Intolerant Subjects with Cardiovascular Disease (TRANSCEND) trial (see design later), the effect of telmisartan on LVH (electrocardiogram criteria) was 
studied in patients at high vascular risk without known heart failure. ${ }^{17,49}$ In TRANSCEND trial, telmisartan $80 \mathrm{mg}$ was more effective than placebo in reducing LVH $(P=0.0017$, Figure 1). ${ }^{50}$ Moreover, new-onset LVH decreased by $37 \%$ in the telmisartan group. In the ONTARGET, LVH prevalence was slightly lower with telmisartan than with ramipril $(P=0.07)$. It is also important to be aware of this positive effect, given that LVH is involved in the development of heart failure and arrhythmia.

\section{Arterial wall damage}

Angiotensin II plays a key role in the initiation and exacerbation of atherosclerosis, and RAAS inhibitors seem to occupy a special place among vascular protective treatments. Several vascular parameters are used as CV risk markers, including the presence of vascular hypertrophy (increased intima-media thickness, IMT) and plaques. Interestingly, it has been shown in patients with hypertension that telmisartan significantly reduces carotid IMT and carotid wall cross-sectional area than does ramipril. ${ }^{48}$

Arterial wall stiffness, which can be assessed using carotid-to-femoral pulse wave velocity (PWV), is another CV risk marker. It is responsible for an increase in systolic BP and a relative decrease in diastolic BP. Reduced arterial stiffness on treatment is associated with decreases in morbidity and mortality, independently of BP reduction. In TRANSCEND trial, the patients taking telmisartan $80 \mathrm{mg}$ tended to have a lower PWV (difference of $0.5 \mathrm{~m} / \mathrm{s}$ ) than those taking placebo after 2 years of treatment (Roland Asmar, pers comm).

\section{Using telmisartan to prevent CV events \\ CV prevention}

The beneficial role of RAAS inhibition in the secondary prevention of $\mathrm{CV}$ and renal diseases, and in patients with diabetes at high $\mathrm{CV}$ risk, has been clearly demonstrated. However, what is the best therapeutic strategy in this type of patient: ACE inhibitors, ARBs, or a combination of both? The HOPE trial compared the effect of ramipril $10 \mathrm{mg}$ with placebo for a mean follow-up period of 5 years in 9,297 patients at high CV risk who had evidence of vascular disease or diabetes plus another CV risk factor. ${ }^{18}$ In this trial, a primary outcome (myocardial infarction, stroke, or death from $\mathrm{CV}$ causes) was reached less often in patients receiving ramipril $(-22 \%, P<0.001)$. The recent ONTARGET included 25,620 patients (mean age, 66.4 years; $73 \%$ men and $38 \%$ patients with diabetes) who were at high risk for vascular events. ${ }^{17}$ On inclusion, 85\% of patients had a CV pathology, 49\% had already experienced myocardial infarction, but none had presented heart failure, $21 \%$ were had a stroke, and 69\% had hypertension. These patients were being well managed (62\% were taking

\section{Blood pressure difference (T-P) CV death, $\mathrm{Ml}$ and stroke prevalence}

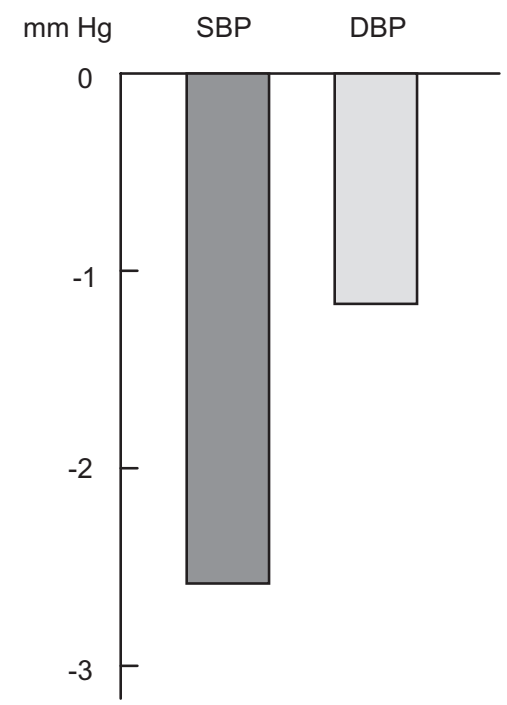

LVH prevalence

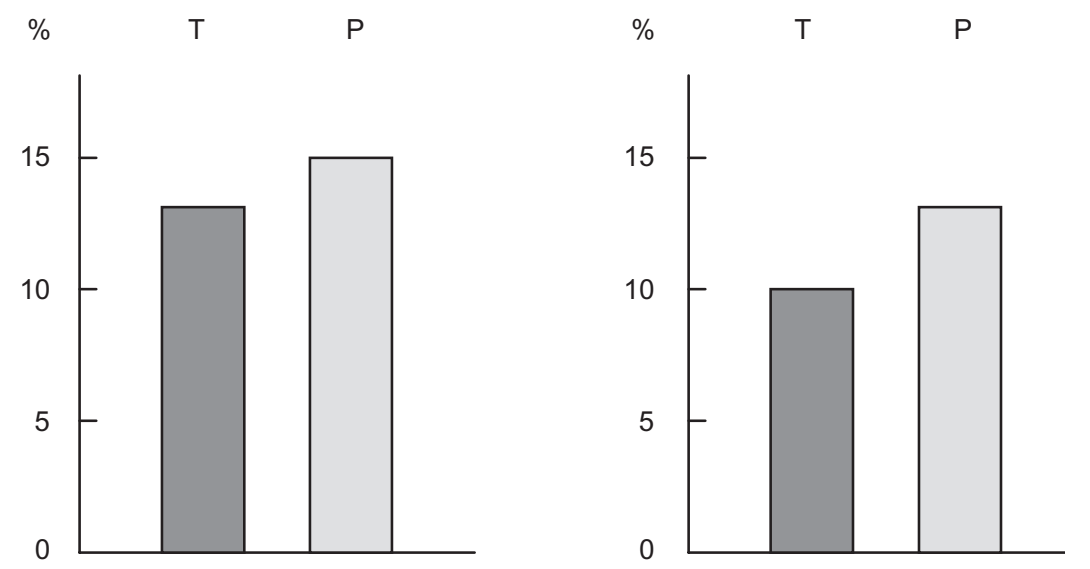

Figure I Beneficial effects of telmisartan compared with placebo at the end of the TRANSCEND study: blood pressure (difference between both groups: $-2.6 /-1.1$ mmHg), ${ }^{49}$ cardiovascular events $(13.0 \%$ vs $14.8 \%, P=0.048),{ }^{49}$ and electric left ventricular hypertrophy $(9.9 \%$ vs $12.8 \%, P=0.0017) .{ }^{50}$

Abbreviations: CV, cardiovascular; DBP, diastolic blood pressure; LVH, left ventricular hypertrophy; MI, myocardial infarction; P, placebo; SBP, systolic blood pressure; $\mathrm{T}$, telmisartan. 
a statin and $76 \%$ were taking aspirin). The subjects were randomized to receive either telmisartan up to the $80 \mathrm{mg}$ or ramipril up to $10 \mathrm{mg}$ per day, or combination therapy. The aim of this trial was 2-fold: (1) to demonstrate that telmisartan was more effective against the incidence of $\mathrm{CV}$ events (primary composite outcome: death from $\mathrm{CV}$ causes, myocardial infarction, stroke, or hospitalization for heart failure) and tolerated better than ramipril; and (2) to determine whether the combination of telmisartan and ramipril was more effective than monotherapy with ramipril against the incidence of $\mathrm{CV}$ events. The main results of the ONTARGET showed that, after a mean follow-up period of 56 months, the overall incidence of $\mathrm{CV}$ events was identical with telmisartan alone (16.7\%), with ramipril alone $(16.5 \%)$, and with the combination of telmisartan and ramipril (16.3\%). In this trial, the patients in the telmisartan group and the combination-therapy group had slightly lower BP levels throughout the trial period (mean reductions of $0.9 / 0.6 \mathrm{mmHg}$ and $2.4 / 1 / 4 \mathrm{mmHg}$, respectively) than the patients in the ramipril group. This is the first trial to show that an ARB, telmisartan, is as effective as an ACE inhibitor, ramipril, in terms of reducing the risk of all types of $\mathrm{CV}$ complications occurring in patients at high vascular risk. Interestingly, the same trial showed that the main benefit of reducing clinical systolic BP to below $130 \mathrm{mmHg}$ was the reduction in the incidence of stroke, but the incidence of myocardial infarction was unaffected. ${ }^{51}$

Although ACE inhibitors are indicated in many clinical situations, around $20 \%$ of patients cannot tolerate them due to coughing, hypotension, and impaired renal function. As ACE inhibitor-intolerant patients at high vascular risk could not be included in the ONTARGET, a separate trial was created for them, namely the TRANSCEND trial. ${ }^{49}$ A total of 5,926 patients were included in this trial, and the main result showed that, after a median follow-up period of 56 months with telmisartan $80 \mathrm{mg}$ and placebo, there was a similar incidence of CV events (15.7\% vs 17.0\%). However, in the TRANSCEND trial, telmisartan significantly reduced the risk of the secondary composite outcome (CV death, myocardial infarction, or stroke, ie, the HOPE trial end point) $(P=0.048$, Figure 1).

\section{Atrial fibrillation}

Atrial fibrillation is associated with increased cardiac and vascular risks, particularly stroke. A meta-analysis by Healey et al demonstrates that ACE inhibitors and ARBs reduce the relative risk of atrial fibrillation by $38 \%$ $(P=0.0002)$, with both classes inducing a similar reduction. ${ }^{52}$ This positive effect of RAAS inhibitors is seen, in particular, in patients with heart failure $(-44 \%)$. In the ONTARGET, which was conducted on patients without known heart failure, both drugs (telmisartan and ramipril) had similar effects on new-onset atrial fibrillation. ${ }^{17}$

\section{Cerebrovascular prevention}

As mentioned earlier, both ACE inhibitors and ARBs have a positive effect at the vascular level. But what about the secondary prevention of stroke? The PROGRESS trial of 6,105 patients showed that a combination of perindopril and indapamide reduces the risk of recurrent stroke by $28 \%$ compared with placebo after a 4-year follow-up period. ${ }^{53}$ The PROFESS trial compared telmisartan $80 \mathrm{mg}$ with placebo over 2.5 years in 20,332 patients who had recently experienced an ischemic stroke. ${ }^{54}$ Stroke recurrence (the primary outcome) was similar in both groups $(P=0.23)$, and the same was true for all major $\mathrm{CV}$ events. We should however remember that, in this trial, $37 \%$ of patients in the placebo group received an ACE inhibitor, $47 \%$ received a statin, and $100 \%$ received aspirin.

\section{Safety and tolerance}

Besides efficacy, safety and tolerance are also the essential properties of a drug, especially when it is used in the long term, as is the case with antihypertensive medications. Several trials have shown that ARBs are well tolerated and are probably even the best-tolerated class of antihypertensive drugs. ${ }^{55}$ Several trials have shown that telmisartan is well tolerated, in particular, compared with placebo and an ACE inhibitor.

The PRISMA trial showed that the tolerance of both ramipril and telmisartan was good, although coughing was reported less frequently with the ARB than with the ACE inhibitor. ${ }^{24}$ In the ONTARGET, patients discontinued telmisartan less often than ramipril $(21.0 \%$ vs $23.7 \%, P=0.02) .{ }^{17}$ Similarly, fewer patients had experienced coughing $(1.1 \%$ vs $4.2 \%, P<0.001)$ or angioedema $(0.1 \%$ vs $0.3 \%, P=0.01)$ on treatment with telmisartan. However, although the incidence of syncope did not increase, the rate of hypotensive symptoms with telmisartan $(2.6 \%$ vs $1.7 \%, P<0.001)$ was higher. An important fact to note is that there were as many renal events with telmisartan (10.6\%) as with ramipril (10.2\%), and in particular, a similar number of patients presented with doubled creatinine levels. Likewise, the number of patients whose potassium levels increased by more than $5.5 \mathrm{mmol} / \mathrm{L}$ was similar in both monotherapy groups, but higher with the combination-therapy groups.

The tolerance of telmisartan was also compared with that of amlodipine. In subjects older than 60 years, 
telmisartan + HCTZ was better tolerated than the calcium channel blocker + HCTZ. ${ }^{31}$

The consequences of good tolerance of telmisartan are essentially improved safety of use and compliance.

In the ONTARGET, a combination of telmisartan and ramipril induced more side effects and laboratory abnormalities than ramipril alone. ${ }^{17}$ In particular, syncope was more common $(0.3 \%$ vs $0.2 \%, P=0.03)$, as were episodes of renal failure $(1.1 \%$ vs $0.7 \%, P<0.001)$ and hyperkalemia.

\section{Conclusion: telmisartan's place in the therapeutic arsenal}

The modern approach to treating $\mathrm{CV}$ diseases should take account not only of individual CV risk factors but also of the patient's overall CV risk. Furthermore, it is essential to have access to drugs that have been proven effective for both primary and secondary preventions. This is why telmisartan warrants a special place in the therapeutic arsenal. It is effective in reducing BP, it has a favorable metabolic profile, it has been proven effective in patients at high vascular risk, and it is well tolerated. These data, mostly derived from the ONTARGET and TRANSCEND trial, were taken into account when the European Society of Hypertension recently reappraised its guidelines on hypertension management. ${ }^{33}$ Finally, in 2010, telmisartan is indicated for essential hypertension in adults and for the prevention of $\mathrm{CV}$ disease in patients with (1) manifest atherothrombotic CV disease (a history of coronary heart disease, stroke, or peripheral arterial disease) or (2) type 2 diabetes mellitus with documented target-organ damage.

\section{Disclosures}

The authors do not have any financial interests or conflicts related to this manuscript.

\section{References}

1. Mancia G, De Backer G, Dominiczak A, et al; for Management of Arterial Hypertension of the European Society of Hypertension and European Society of Cardiology. 2007 guidelines for the management of arterial hypertension: the task force for the management of arterial hypertension of the European Society of Hypertension (ESH) and of the European Society of Cardiology (ESC). J Hypertens. 2007; 25:1105-1187.

2. De Backer G, Ambrosioni E, Borch-Johnsen K, et al; for Third Joint Task Force of European and Other Societies on Cardiovascular Disease Prevention in Clinical Practice. European guidelines on cardiovascular disease prevention in clinical practice. Third joint task force of European and other societies on cardiovascular disease prevention in clinical practice. Eur Heart J. 2003;24: $1601-1610$.
3. Mazzaglia G, Ambrosioni E, Alacqua M, et al. Adherence to antihypertensive medications and cardiovascular morbidity among newly diagnosed hypertensive patients. Circulation. 2009;120: 1598-1605.

4. Chapman RH, Ferrufino CP, Kowal SL, Classi P, Roberts CS. The cost and effectiveness of adherence-improving interventions for antihypertensive and lipid-lowering drugs. Int J Clin Pract. 2010;64:169-181.

5. Burnier M, Brunner HR. Angiotensin II receptor antagonists. Lancet. 2000;355:637-645.

6. Vanderheyden PM, Fierens FL, Vauquelin G. Angiotensin II type 1 receptor antagonists. Why do some of them produce insurmountable inhibition? Biochem Pharmacol. 2000;60:1557-1563.

7. Song JC, White CM. Olmesartan medexomil (CS-866) an angiotensin II receptor blocker for treatment of hypertension. Formulary. 2001;236:487-499.

8. Kakuta H, Sudoh K, Sasamata M, Yamagishi S. Telmisartan has the strongest binding affinity to angiotensin II type 1 receptor: comparison with other angiotensin II type 1 receptor blockers. Int J Clin Pharmacol Res. 2005;25:41-46.

9. Goebel M, Clemenz M, Unger T. Effective treatment of hypertension by AT(1) receptor antagonism: the past and future of telmisartan. Expert Rev Cardiovasc Ther. 2006;4:615-629.

10. Maillard MP, Perregaux $C$, Centeno $C$, et al. In vitro and in vivo characterization of the activity of telmisartan: an insurmountable angiotensin II receptor antagonist. $J$ Pharmacol Exp Ther. 2002;302:1089-1095.

11. Remková A, Kratochvíl'ová H, Durina J. Impact of the therapy by renin-angiotensin system targeting antihypertensive agents perindopril versus telmisartan on prothrombotic state in essential hypertension. J Hum Hypertens. 2008;22:338-345.

12. Benson SC, Pershadsingh HA, Ho CI, et al. Identification of telmisartan as a unique angiotensin II receptor antagonist with selective PPARgamma-modulating activity. Hypertension. 2004;43: 993-1002.

13. Pershadsingh HA, Kurtz TW. Insulin-sensitizing effects of telmisartan: implications for treating insulin-resistant hypertension and cardiovascular disease. Diabetes Care. 2004;27:1015.

14. Miura Y, Yamamoto N, Tsunekawa S, et al. Replacement of valsartan and candesartan by telmisartan in hypertensive patients with type 2 diabetes: metabolic and antiatherogenic consequences. Diabetes Care. 2005;28:757-758.

15. Vitale C, Mercuro G, Castiglioni C, et al. Metabolic effect of telmisartan and losartan in hypertensive patients with metabolic syndrome. Cardiovasc Diabetol. 2005;15:6.

16. Abuissa H, Jones PG, Marso SP, O'Keefe JH Jr. Angiotensin-converting enzyme inhibitors or angiotensin receptor blockers for prevention of type 2 diabetes: a meta-analysis of randomized clinical trials. J Am Coll Cardiol. 2005;46:821-826.

17. Yusuf S, Teo KK, Pogue J, et al; for ONTARGET Investigators. Telmisartan, ramipril, or both in patients at high risk for vascular events. N Engl J Med. 2008;358:1547-1559.

18. Yusuf S, Sleight P, Pogue J, Bosch J, Davies R, Dagenais G. Effects of an angiotensin-converting-enzyme inhibitor, ramipril, on cardiovascular events in high-risk patients. The Heart Outcomes Prevention Evaluation Study Investigators. $N$ Engl J Med. 2000;342:145-153.

19. Delles C, Raff U, Mimran A, Fauvel JP, Ruilope LM, Schmieder RE. Effects of telmisartan and ramipril on adiponectin and blood pressure in patients with type 2 diabetes. Am J Hypertens. 2008;21:1330-1336.

20. Hopkins TA, Ouchi N, Shibata R, Walsh K. Adiponectin actions in the cardiovascular system. Cardiovasc Res. 2007;74:11-18.

21. Schmieder RE, Delles C, Mimran A, Fauvel JP, Ruilope LM. Impact of telmisartan versus ramipril on renal endothelial function in patients with hypertension and type 2 diabetes. Diabetes Care. 2007;30:1351-1356.

22. Baguet JP, Legallicier B, Auquier P, Robitail S. Updated meta-analytical approach to the efficacy of antihypertensive drugs in reducing blood pressure. Clin Drug Investig. 2007;27:735-753. 
23. Lacourcière Y, Neutel JM, Davidai G, Koval S. A multicenter, 14-week study of telmisartan and ramipril in patients with mild-tomoderate hypertension using ambulatory blood pressure monitoring. Am J Hypertens. 2006;19:104-112.

24. Williams B, Gosse P, Lowe L, Harper R; for PRISMA I Study Group. The prospective, randomized investigation of the safety and efficacy of telmisartan versus ramipril using ambulatory blood pressure monitoring (PRISMA I). J Hypertens. 2006;24:193-200.

25. Gosse P, Neutel JM, Schumacher H, LacourcièreY, Williams B, Davidai G. The effect of telmisartan and ramipril on early morning blood pressure surge: a pooled analysis of two randomized clinical trials. Blood Press Monit. 2007;12:141-147.

26. White WB, Murwin D, Chrysant SG, Koval SE, Davidai G, Guthrie R. Effects of the angiotensin II receptor blockers telmisartan versus valsartan in combination with hydrochlorothiazide: a large, confirmatory trial. Blood Press Monit. 2008;13:21-27.

27. Mallion J, Siché J, Lacourcière Y. ABPM comparison of the antihypertensive profiles of the selective angiotensin II receptor antagonists telmisartan and losartan in patients with mild-to-moderate hypertension. J Hum Hypertens. 1999;13:657-664.

28. Bakris G. Comparison of telmisartan vs valsartan in the treatment of mild to moderate hypertension using ambulatory blood pressure monitoring. J Clin Hypertens (Greenwich). 2002;4 Suppl 1: S26-S31.

29. Neutel JM, Littlejohn TW, Chrysant SG, Singh A; for Telmisartan Study Group. Telmisartan/hydrochlorothiazide in comparison with losartan/hydrochlorothiazide in managing patients with mild-to-moderate hypertension. Hypertens Res. 2005;28: 555-563.

30. Sharma AM, Davidson J, Koval S, Lacourcière Y. Telmisartan/hydrochlorothiazide versus valsartan/hydrochlorothiazide in obese hypertensive patients with type 2 diabetes: the SMOOTH study. Cardiovasc Diabetol. 2007;6:28

31. Neldam S, Edwards C; for ATHOS Study Group. Telmisartan plus HCTZ vs amlodipine plus HCTZ in older patients with systolic hypertension: results from a large ambulatory blood pressure monitoring study. Am J Geriatr Cardiol. 2006;15:151-160.

32. Mancia G, Parati G, Bilo G, et al. Effects of ramipril, telmisartan and their combination on ambulatory blood pressure in an ONTARGET substudy [abstract]. J Hypertens. 2009;27 Suppl 4:S168.

33. Mancia G, Laurent S, Agabiti-Rosei E, et al. Reappraisal of European guidelines on hypertension management: a European Society of Hypertension task force document. J Hypertens. 2009;27: 2121-2158.

34. Brenner BM, Cooper ME, de Zeeuw D, et al; for RENAAL Study Investigators. Effects of losartan on renal and cardiovascular outcomes in patients with type 2 diabetes and nephropathy. $N$ Engl $J$ Med. 2001;345:861-869.

35. Lewis EJ, Hunsicker LG, Clarke WR, et al; for Collaborative Study Group. Renoprotective effect of the angiotensin-receptor antagonist irbesartan in patients with nephropathy due to type 2 diabetes. $N$ Engl J Med. 2001;345:851-860.

36. Parving HH, Lehnert H, Bröchner-Mortensen J, Gomis R, Andersen S, Arner P; for Irbesartan in Patients with Type 2 Diabetes and Microalbuminuria Study Group. The effect of irbesartan on the development of diabetic nephropathy in patients with type 2 diabetes. $N$ Engl J Med. 2001;345:870-878.

37. Makino H, Haneda M, Babazono T, et al; for INNOVATION Study Group. Prevention of transition from incipient to overt nephropathy with telmisartan in patients with type 2 diabetes. Diabetes Care. 2007;30:1577-1578.

38. Barnett AH, Bain SC, Bouter P, et al; for Diabetics Exposed to Telmisartan and Enalapril Study Group. Angiotensin-receptor blockade versus converting-enzyme inhibition in type 2 diabetes and nephropathy. N Engl J Med. 2004;351:1952-1961.
39. Bakris G, Burgess E, Weir M, Davidai G, Koval S; for AMADEO Study Investigators. Telmisartan is more effective than losartan in reducing proteinuria in patients with diabetic nephropathy. Kidney Int. 2008;74:364-369.

40. Galle J, Schwedhelm E, Pinnetti S, Böger RH, Wanner C; for VIVALDI investigators. Antiproteinuric effects of angiotensin receptor blockers: telmisartan versus valsartan in hypertensive patients with type 2 diabetes mellitus and overt nephropathy. Nephrol Dial Transplant. 2008;23:3174-3183.

41. Vogt L, Navis G, Köster J, Manolis AJ, Reid JL, de Zeeuw D; for Angiotensin II Receptor Antagonist telmisartan Micardis in Isolated Systolic hypertension (ARAMIS) study group. The angiotensin II receptor antagonist telmisartan reduces urinary albumin excretion in patients with isolated systolic hypertension: results of a randomized, double-blind, placebo-controlled trial. J Hypertens. 2005;23:2055-2061.

42. Kunz R, Friedrich C, Wolbers M, Mann JF. Meta-analysis: effect of monotherapy and combination therapy with inhibitors of the renin angiotensin system on proteinuria in renal disease. Ann Intern Med. 2008;148:30-48.

43. Mann JF, Schmieder RE, McQueen M, et al; for ONTARGET investigators. Renal outcomes with telmisartan, ramipril, or both, in people at high vascular risk (the ONTARGET study): a multicentre, randomised, double-blind, controlled trial. Lancet. 2008;372: 547-553.

44. Cohn JN, Tognoni G; for Valsartan Heart Failure Trial Investigators. A randomized trial of the angiotensin-receptor blocker valsartan in chronic heart failure. N Engl J Med. 2001;345:1667-1675.

45. McMurray JJ, Ostergren J, Swedberg K, et al; for CHARM Investigators and Committees. Effects of candesartan in patients with chronic heart failure and reduced left-ventricular systolic function taking angiotensin-converting-enzyme inhibitors: the CHARM-Added trial. Lancet. 2003;362:767-771.

46. Galzerano D, Tammaro P, Cerciello A, et al. Freehand three-dimensional echocardiographic evaluation of the effect of telmisartan compared with hydrochlorothiazide on left ventricular mass in hypertensive patients with mild-to-moderate hypertension: a multicentre study. J Hum Hypertens. 2004;18:53-59.

47. Galzerano D, Tammaro P, del Viscovo L, et al. Three-dimensional echocardiographic and magnetic resonance assessment of the effect of telmisartan compared with carvedilol on left ventricular mass a multicenter, randomized, longitudinal study. Am J Hypertens. 2005; $18: 1563-1569$.

48. Petrovic I, Petrovic D, Vukovic N, et al. Ventricular and vascular remodelling effects of the angiotensin II receptor blocker telmisartan and/or the angiotensin-converting enzyme inhibitor ramipril in hypertensive patients. J Int Med Res. 2005;33 Suppl 1:39A-49A.

49. Yusuf S, Teo K, Anderson C, et al; for Telmisartan Randomised AssessmeNt Study in ACE iNtolerant subjects with cardiovascular Disease (TRANSCEND) Investigators. Effects of the angiotensin-receptor blocker telmisartan on cardiovascular events in high-risk patients intolerant to angiotensin-converting enzyme inhibitors: a randomised controlled trial. Lancet. 2008;372: 1174-1183.

50. Verdecchia P, Sleight P, Mancia G, et al; for ONTARGET/TRANSCEND Investigators. Effects of telmisartan, ramipril, and their combination on left ventricular hypertrophy in individuals at high vascular risk in the ongoing telmisartan alone and in combination with ramipril global end point trial and the telmisartan randomized assessment study in ACE intolerant subjects with cardiovascular disease. Circulation. 2009;120:1380-1389.

51. Sleight P, Redon J, Verdecchia P, et al; for ONTARGET investigators. Prognostic value of blood pressure in patients with high vascular risk in the ongoing telmisartan alone and in combination with ramipril global endpoint trial study. J Hypertens. 2009;27:1360-1369. 
52. Healey JS, Baranchuk A, Crystal E, et al. Prevention of atrial fibrillation with angiotensin-converting enzyme inhibitors and angiotensin receptor blockers: a meta-analysis. J Am Coll Cardiol. 2005;45:1832-1839.

53. PROGRESS Collaborative Group. Randomised trial of a perindopril-based blood-pressure-lowering regimen among 6,105 individuals with previous stroke or transient ischaemic attack. Lancet. 2001;358:1033-1041.
54. Yusuf S, Diener HC, Sacco RL, et al; for PRoFESS Study Group. Telmisartan to prevent recurrent stroke and cardiovascular events. N Engl J Med. 2008;359:1225-1237.

55. Gerth WC. Compliance and persistence with newer antihypertensive agents. Curr Hypertens Rep. 2002;4:424-433.

Integrated Blood Pressure Control

\section{Publish your work in this journal}

Integrated Blood Pressure Control is an international, peer-reviewed open-access journal focusing on the integrated approach to managing hypertension and risk reduction. Treating the patient and comorbidities together with diet and lifestyle modification and optimizing healthcare resources through a multidisciplinary team approach constitute key
Dovepress

features of the journal. This journal is indexed on American Chemical Society's Chemical Abstracts Service (CAS). The manuscript management system is completely online and includes a very quick and fair peerreview system, which is all easy to use. Visit http://www.dovepress.com/ testimonials.php to read real quotes from published authors.

Submit your manuscript here: http://www.dovepress.com/integrated-blood-pressure-control-journal 